\title{
Aulas Remotas E Ensino A Distância No Período Pós-Pandemia: Um Olhar Sobre O Ensino Jurídico Pela Perspectiva Dos Universitários Em Fortaleza
}

\author{
Daiane de Queiroz* \\ Universidade de Fortaleza, Programa de Pós-Graduação em Direito, Fortaleza-CE, Brasil. \\ iD https://orcid.org/oooo-0oo2-9798-4776
}

Ana Carolina N. G. F. Gomes**

Universidade de Fortaleza, Programa de Pós-Graduação em Direito, Fortaleza-CE, Brasil.

(D) https://orcid.org/oooo-0003-2350-9769

Mônica Mota Tassigny***

Universidade de Fortaleza, Programa de Pós-Graduação em Direito, Fortaleza-CE, Brasil.

Resumo: Em virtude do distanciamento social ocasionado pela pandemia da COVID-19, o ensino remoto passou a ser permitido pela Resolução $\mathrm{n}^{0} 342$, de $17 \mathrm{de}$ março de 2020. Foi autorizada, em caráter excepcional, a substituição das disciplinas presenciais em andamento por aulas que utilizem meios e tecnologias de informação e comunicação (TICs'). A partir dessa prática, busca-se analisar a opinião dos alunos de cursos de graduação em Direito de Fortaleza sobre as aulas remotas, sobre disciplinas em Educação a Distância (EAD) e sobre as perspectivas para o futuro do ensino jurídico. Trata-se de pesquisa bibliográfica, documental e de campo, com amostra de 194 alunos do ensino superior da cidade de Fortaleza. Quanto às abordagens, utiliza-se tanto a qualitativa quanto a quantitativa. Verifica-se que existe a preferência da maioria, $74,7 \%$, pelo retorno para as aulas presenciais, com a possibilidade de um percentual de aulas remotas, porém inferior a 30\%. Como resultado, espera-se contribuir para a melhoria do ensino jurídico no Brasil a partir da análise desse novo mecanismo de ensino presencial remoto.

Palavras-chave: Pandemia.Covid-19. Educação jurídica. Aulas remotas. Curso de Direito.

* Mestranda em Direito Constitucional e Teoria Política pela Universidade de Fortaleza. E-mail: dayqrz@gmail.com

** Mestranda em Direito Constitucional pela UNIFOR. Defensora Pública do Estado do Ceará. E-mail: acngondim@edu.unifor.br

*** Doutorado em Sócio-Economie du développement - Ecole des Hautes Études en Sciences Sociales e doutorado em Educação pela Universidade Federal do Ceará. Professora titular da Universidade de Fortaleza. E-mail: monica.tass@gmail.com

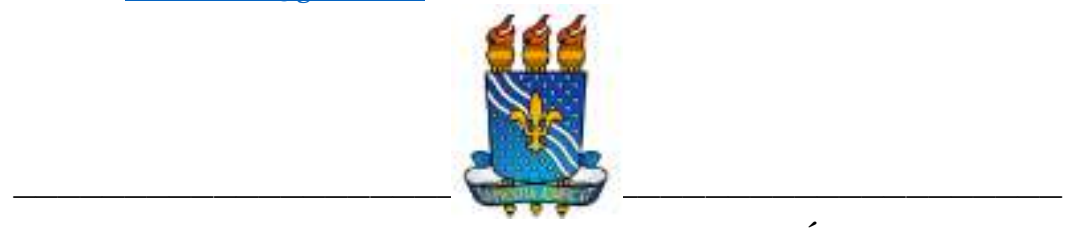

UNIVERSIDADE FEDERAL DA PARAÍBA

Programa de Pós-Graduação em Ciências Jurídicas

DOI: https://doi.org/10.22478/ufpb.1678-2593.2020v19n42.53775 


\title{
Aulas Remotas E Ensino A Distância No Período Pós-Pandemia: Um Olhar Sobre O Ensino Jurídico Pela Perspectiva Dos Universitários Em Fortaleza
}

\author{
Daiane Queiroz
}

Ana Carolina Neiva Gondim Ferreira Gomes

Mônica Mota Tassigny

\section{INTRODUÇÃO}

A pandemia causada pelo coronavírus SARS-CoV-2, causador da doença COVID-19, em 2020, causou impactos na sociedade em vários aspectos, seja para os indivíduos, seja para a coletividade. Os impactos na saúde pública e na economia são objetos de notícias diárias nos veículos de comunicação, bem como de pesquisas científicas. A ciência está presente, seja na busca de remédio ou vacinas, seja na análise sobre a questão política e sobre as medidas de prevenção e combate adotadas pelos governos.

Em razão das medidas de isolamento social, em relação à educação, a pandemia trouxe a necessidade imediata de adoção de tecnologia de ensino virtual. A prática da educação a distância passou a ser regra e não mais uma opção, em razão da proibição legal de aulas presenciais.

No caso do Brasil, foi publicada a Portaria 343, de 17 de março de 2020, sobre a substituição das aulas presenciais por aulas em meios digitais enquanto durar a situação da pandemia da COVID-19.

A norma referida ressalta o caráter provisório da permissão enquanto durar a pandemia, bem como possibilita também que as 
instituições suspendam as aulas para posterior retorno. A norma excepcionou do permissivo as práticas profissionais de estágios e de laboratório.

O Conselho Nacional de Educação se reuniu no dia 28 de abril de 2020 e aprovou, por unanimidade, parecer que foi homologado em 29 de maio de 2020, contendo diretrizes para orientar escolas da educação básica e Instituições de Ensino Superior durante a pandemia do coronavírus. Para o ensino superior, foi sugerida a continuidade das atividades de ensino de maneira não presencial.

Em relação ao Ceará, o Governador do Estado do Ceará editou o Decreto $\mathrm{n}^{0} 33.510$, no dia 16 de março de 2020, suspendendo o ensino presencial, ressaltando que a suspensão não significava que durante o período de suspensão ocorressem atividades de natureza remota.

No dia 28 de março de 2020 a suspensão foi prorrogada pelo Decreto $\mathrm{n}^{0} 33.530$ e sucessivamente foram publicados novos decretos prorrogando-as, Decreto $\mathrm{n}^{\mathrm{o}} 33.536$, de 05 de abril de 2020, e Decreto $\mathrm{n}^{0}$ 33.544, de 19 de abril de 2020. Registre-se que no dia 5 de maio de 2020 foi publicado o Decreto Estadual $n^{0} 33.574$, com medidas ainda mais rígidas, mantidas pelo Decreto $\mathrm{n}^{\mathrm{o}}$ 33.594. Somente com o Decreto $\mathrm{n}^{0} 33.608$, de 30 de maio, foram flexibilizadas as medidas rígidas, porém sem retorno das aulas presenciais.

O ensino a distância no Brasil já existia antes da pandemia. As perspectivas surgiam à medida que se avançava em relação à possibilidade da tecnologia, passando pelo correio, pelo rádio, pela televisão e, atualmente, através da internet.

A aplicação do ensino a distância descortina a questão das desigualdades sociais, pois evidencia as condições financeiras diferentes entre estudantes do sistema público e do sistema privado de ensino, especialmente no Brasil, país de dimensão continental.

Espera-se que, com o barateamento da tecnologia e a inclusão de mais pessoas, seja possível ocorrer também a expansão do sistema de educação a distância, seja em tempo real, seja de forma gravada, permitindo maior acesso ao ensino superior. 
Em relação à evolução e ao reconhecimento jurídico do ensino a distância no Brasil, após decretos e portarias, destaca-se a promulgação da Lei de Diretrizes e Bases da Educação, Lei no 9.394, de 1996, como marco legal. A lei ainda vigente prevê o incentivo e o desenvolvimento de programas de ensino a distância em todos os níveis e modalidades de ensino e de educação continuada.

A partir da realidade do ensino e do avanço da tecnologia, são suscitados debates sobre qual deveria ser o formato ideal de aulas e como deveria ser o uso dessa tecnologia. Ainda que exista resistência e crítica sobre a educação a distância, passou a ser crescente o número de disciplinas nessa modalidade.

Em relação ao ensino jurídico, antes da pandemia já existiam, no currículo das Instituições de Ensino Superior, disciplinas na modalidade EaD à disposição dos alunos em percentual referente ao total do programa. Com a suspensão de aulas em razão da pandemia da COVID-19, as demais disciplinas, que antes eram presenciais, passaram também a ocorrer de maneira remota.

A tecnologia permite que a transmissão de aulas online ocorra com imagem e áudio, inclusive em tempo real, e com ferramentas de interação entre os envolvidos no processo de aprendizagem, de modo que a pesquisa se justifica tanto pela atualidade promovida pela portaria em relação à educação remota, como pela necessidade de se investigar a opinião dos estudantes.

Diante desse cenário, indaga-se como os alunos avaliam as aulas remotas em tempo real e as aulas das disciplinas EaD nas instituições de ensino jurídico em Fortaleza; e qual a opinião sobre as perspectivas para o futuro do ensino jurídico. O trabalho tem como objetivo geral analisar a opinião desses estudantes sobre as aulas remotas no que se refere ao período vivido durante a pandemia da COVID-19; sobre aulas EaD disponíveis anteriormente; e, como objetivo específico, intenta identificar perspectivas para o futuro do ensino jurídico. 
A pesquisa é bibliográfica, documental e de campo, com abordagem qualitativa e quantitativa. Foi aplicado questionário de opinião com participantes não identificados, nos termos do artigo $1^{\circ}$, inciso I, da Resolução $\mathrm{n}^{0}$ 510, de 7 de abril de 2016, do Ministério da Saúde, o qual dispõe sobre normas aplicáveis a pesquisas que envolvam utilização de dados diretamente obtidos com os participantes.

Para a elaboração do questionário, foi utilizada a plataforma Google Forms, sendo posteriormente enviado na forma de link, de forma aleatória, para alguns professores e alunos que replicaram para outras pessoas, a partir da técnica snowball. A amostra utilizada foi de 194 alunos e o questionário ficou disponível para preenchimento dos dias 14 a 30 de maio de 2020.

No trabalho é definido o ensino remoto e diferenciado do ensino a distância (EaD). Em seguida, são abordados os dispositivos constitucionais e a Agenda 2030 da ONU, relacionados ao direito à educação. O ensino jurídico é analisado a partir das tecnologias de ensino TICs e metodologias ativas, bem como são analisados os questionários de opinião dos alunos e, ao final, através de estudo qualitativo e quantitativo, verificadas as possibilidades para o futuro.

\section{ENSINO REMOTO E DISTINÇÃO COM O ENSINO À DISTÂNCIA ANTES DA PANDEMIA DA COVID-19}

A distinção entre os termos ensino remoto, ensino a distância e mesmo educação a distância são importantes para que se compreenda a situação do Brasil e as decisões políticas em relação ao tema.

Para compreender a distinção entre ensino remoto e ensino à distância, faz-se necessário definir educação a distância:

Educação a distância é o aprendizado planejado que ocorre normalmente em um lugar diferente do local do ensino, exigindo técnicas especiais de criação do curso e de instrução, comunicação por meio de várias tecnologias e 
disposições organizacionais e administrativas especiais. (MOORE, 2007, p. 2)

$\mathrm{Na}$ definição são especificados quatro aspectos importantes, quais sejam, a diferenciação entre aprendizado e ensino; aprendizado entendido como algo que é planejado; aprendizado que ocorre normalmente em lugar diferente do local de ensino; e comunicação que se estabelece por meio de diversas tecnologias.

Prossegue Moore (2007, p. 2) enfatizando que o tipo de aprendizado que é estudado na educação é o aprendizado planejado, ou seja, o aluno se propõe a deliberadamente aprender, sendo auxiliado pelo seu professor, que também de forma deliberada cria meios para ajudá-lo a aprender.

Ademais, a regra é que o professor não esteja presente, o que não significa que ocasionalmente não possa existir alguma reunião presencial. Utilizam-se termos variados, no entanto, a maioria deles encontra-se de alguma forma enquadrada na definição principal.

Portanto, ensino à distância não é o mesmo que o ensino remoto em tempo real, pois, apesar de igualmente mediado por tecnologia, esse pressupõe a presença em tempo real do professor, ocorrendo em local diferente, porém de maneira sincrônica.

Realizada essa diferenciação teórica, quanto à legislação brasileira, a Lei de Diretrizes e Bases da Educação dispõe, no art. 8o, sobre o termo ensino à distância, determinando o incentivo e o desenvolvimento de programas que o estimule.

A previsão legal é regulamentada pelo Decreto $\mathrm{n}^{0}$ 9.057, de 2017. A definição para a legislação brasileira de educação a distância está contida nesse decreto:

[...] considera-se educação a distância a modalidade educacional na qual a mediação didático-pedagógica nos processos de ensino e aprendizagem ocorra com a utilização de meios e tecnologias de informação e comunicação, com pessoal qualificado, com políticas de acesso, com acompanhamento e avaliação compatíveis, entre outros, e desenvolva atividades educativas por estudantes e profissionais da educação que estejam em lugares e tempos diversos. (BRASIL, 2017) 
O Decreto $\mathrm{n}^{0}$ 9.057, de 2017, especifica que na educação a distância os estudantes e os profissionais da educação estão em lugares e tempos diversos. O decreto anterior, de 2005, Decreto $n^{0} 5.022$, de 19 de dezembro de 2005, mencionava na definição lugares ou tempos diversos, utilizando-se a conjunção ou. Anteriormente, em 2004, já se verificava na Portaria ${ }^{0}$ 4.059 a utilização do termo disciplinas na modalidade semipresencial.

Essa diferenciação é importante para que se verifique se a modalidade de ensino a distância em tempo real de maneira remota já era prevista pela legislação ou se o Decreto $n^{\circ} 343$, de 2020, publicado em razão da pandemia, dispõe sobre algo totalmente novo.

Em relação aos Cursos de Direito na modalidade $\mathrm{EaD}$, em resposta $^{1}$ enviada pelo Ministério da Educação através do Portal Sistema de Acesso à Informação do Governo Federal, foi esclarecido que nenhum Curso de Direito nessa modalidade de oferta foi autorizado pelo Ministério da Educação.

O Conselho Federal da $\mathrm{OAB}$ ingressou com ação na Justiça Federal contra a União em 2019, com pedido de liminar para que o Ministério da Educação paralisasse os credenciamentos de instituições para Cursos de Direito na modalidade EaD e ingressou, também em maio de 2020, com Ação de Descumprimento de Preceito Fundamental.

A liminar no Processo 1034657-04.2019.4.01.3400 foi indeferida pela $7^{\mathrm{a}}$ Vara Federal Cível da seção judiciária do Distrito Federal e foi negado seguimento à ADPF no 682, de 2020 pelo STF. Assim, é possível o cadastramento de instituições para o fornecimento de serviço de Curso de Direito na modalidade EaD, apesar da ausência de notícia de efetivo credenciamento.

O que existe de fato em relação ao ensino jurídico à distância é o permissivo de que instituições credenciadas para o curso presencial realizem parte do ensino na modalidade à distância. Em 6 dezembro 
de 2019, o Ministério da Educação expediu a Portaria $\mathrm{n}^{0} 2.117$ permitindo que os cursos presenciais ampliassem de $20 \%$ para $40 \%$ a carga horária na modalidade $\mathrm{EaD}$, exceto os cursos de medicina.

Assim, no caso dos cursos de direito de nível superior, existia, mesmo antes da pandemia, permissivo legal para disciplinas online, de acordo com o percentual permitido e com a obediência à Portaria $\mathrm{n}^{0}$ 2.117, de 2019, e seus requisitos, com apresentação do percentual no Projeto Pedagógico do Curso e com a indicação das metodologias a serem utilizadas.

Logo, o fenômeno novo ocorrido em razão da pandemia foi a substituição de aulas presenciais por aulas a distância, sem a observância dos requisitos previstos pela legislação antes da pandemia, bastando que as instituições que optassem pela substituição comunicassem ao Ministério da Educação no período de até quinze dias, conforme disposto na Portaria $\mathrm{n}^{0} 343$, de 17 de março de 2020, com a vedação expressa em relação aos estágios.

Apesar da previsão de liberdade de formato, a notícia era que o ensino adotado seria, em sua maioria, o remoto, ou seja, com aulas em tempo real. Na pesquisa enviada aos alunos, restou verificada a informação. Do total de respostas, $86 \%$ informaram que a instituição adotou aulas presenciais em tempo real, com gravação para quem necessitar assistir em horário diferenciado; 8,8\% de aulas em tempo real sem gravação; e 4,6\% informaram que as aulas são inteiramente gravadas.

\section{TECNOLOGIAS DE INFORMAÇÃO E COMUNICAÇÃO NO ENSINO JURÍDICO}

As Tecnologias da Informação e Comunicação conhecidas como TICs são conceituadas como sinônimos das tecnologias da informação (TI). Porém é um termo universal que confirma o papel da comunicação na contemporânea tecnologia da informação. Verifica-se 
que as TICs consistem em todos os meios técnicos usados para abordar a informação e auxiliar na comunicação (OLIVEIRA; MOURA; SOUSA, 2020 p. 77).

A Portaria $\mathrm{n}^{0}$ 343, de 17 de março de 2020, que autoriza, em caráter excepcional, a substituição das disciplinas presenciais em andamento por aulas que utilizem meios e tecnologias de informação e comunicação enquanto durar a situação da pandemia da COVID-19, marca uma nova era na utilização das tecnologias de informação e comunicação (TICs).

As TICs consistem em TI, bem como quaisquer formas de transmissão de informações, e correspondem a todas as tecnologias que interferem e mediam os processos informacionais e comunicativos das pessoas. Nesse sentido, a tecnologia da informação e comunicação é definida nesta pesquisa como um agrupamento de recursos tecnológicos integrados entre si, que proporcionam, por meio das funções de software e telecomunicações, a automação e a comunicação dos processos de negócios, da pesquisa científica e de ensino e aprendizagem.

O uso de recursos tecnológicos no método de ensino é cada vez mais mandatória, pois torna a aula mais ativa, proporcionando aos discentes um formato diferente de ensino. Para que isso se consubstancie de forma que todos os envolvidos se sintam favorecidos, o assunto das TIC deve estar bem materializado nas Instituições de Ensino Superior -IES (OLIVEIRA; MOURA; SOUSA, 2020 p.76).

As formas de ensinar e aprender podem ser beneficiadas por essas tecnologias, como é exemplo, principalmente, a internet, que traz uma diversidade de informações, como as mídias sociais (Instagram, Facebook, YouTube) e os softwares (Ambientes Virtuais de Aprendizagem - AVA e outros), que auxiliam nessa aprendizagem.

Essa inovação tecnológica desafia a mudança de cultura no campo da educação, mas acontece naturalmente no campo pedagógico, pois o educador, seja da área jurídica, seja de outras áreas, sempre sentiu a necessidade de se atualizar de forma interdisciplinar, 
ou seja, além daquela forma vinculada mais diretamente a sua carreira docente, na constante busca de obtenção de títulos e desenvolvimento de pesquisas.

A terminologia Tecnologia na Educação, conforme Reis (2010, p. 17), envolve a informática, mas não se reduz apenas a está. Compreende também o uso de televisão, de vídeo, de rádio e até mesmo do cinema na promoção da educação.

Infere tecnologia como sendo o resultado da fusão entre ciência e técnica. A concepção de tecnologia educacional pode ser expressa como o conjunto de procedimentos (técnicas) que propõe "facilitar" os métodos de ensino e aprendizagem com o uso de meios (instrumentais, simbólicos ou organizadores) e suas decorrentes transformações culturais (SILVA, 2015, p.32).

Com o isolamento social provocado pela pandemia do coronavírus, as Instituições de Ensino Superior (IES) tiveram quinze dias para se manifestar se adotariam as aulas remotas ou antecipação de férias. As que optaram por sistema remoto, que, segundo o $\mathrm{MEC}^{2}$ ainda estavam coletando a informação e contabilizava até o dia 14 de maio de 2020, apenas cerca de 30\% das instituições. Com isso, em um curto espaço de tempo (dias) as IES tiveram que adequar suas atividades para o ensino remoto com o auxílio das TICs para que os alunos não fossem prejudicados no semestre letivo.

As principais diferenças entre ensino EaD e aulas remotas são as seguintes: no ambiente a distância, as aulas são gravadas para que os alunos estudem quando e onde quiserem, com apoio de tutores, as aulas são permitidas e regulamentadas para determinados cursos, sendo devidamente evidenciado no projeto pedagógico do curso (PPC) quais as disciplinas são a distância e qual a metodologia desenvolvida é própria para a educação a distância, com um ambiente virtual de avaliação (AVA) específico que atenda aos alunos matriculados nessa

2 Solicitação realizada através do Portal de Acesso à Informação do Governo Federal, respondida em 14 de maio de 2020, registrada sob o Protocolo 23480.009307/2020-78. 
modalidade; enquanto que as aulas remotas acontecem em tempo real, por meio de auxílio das TIC's, respeitando dias, horários e mesmos professores previstos nas disciplinas presenciais.

Destaca-se que, na pesquisa de campo, foi questionado sobre o tempo de implemento das aulas remotas nas IES, obtendo-se como resposta que para $25,4 \%$ dos entrevistados houve a substituição de forma imediata, para 37,8\% ocorreu após uma semana do decreto de isolamento social, e 30,6\% migraram para o remoto duas semanas após o decreto.

Evidencia-se na pesquisa que os recurso mais utilizados neste período, conforme respondentes, foram: o Google Meet, com 36,1\%, o Microsoft Teams, com 47,6\%, o YouTube, com 8,9\% e a plataforma Zoom, com $18,6 \%$. Somente $13,1 \%$ indicaram plataforma da própria instituição.

Oliveira, Moura e Sousa (2020, p.86), afirmam que as tecnologias se modificam rapidamente, produzindo-se diversas inovações. $\mathrm{O}$ âmbito educacional é provocado a reinventar e a atingir a finalidade de desenvolver um ensino de boa qualidade com o auxílio das ferramentas tecnológicas:

[...] as tecnologias - sejam elas novas (como o computador e a Internet) ou velhas (como o giz e a lousa) condicionam os princípios, a organização e as práticas educativas e impõem profundas mudanças na maneira de organizar os conteúdos a serem ensinados, as formas como serão trabalhadas e acessadas as fontes de informação, e os modos, individuais e coletivos, como irão ocorrer as aprendizagens (SILVA, 2010, p.76).

A inclusão das TICs no processo de ensino-aprendizagem sempre foi um desafio na sua implementação, o tradicionalismo e conservadorismo, características marcantes do curso de direito, fazem com que essas novidades não sejam exploradas no curso. A implementação das aulas remotas por meio das TICs, impelida como única medida para não prejudicar alunos, professores e instituições, marca um novo momento na valorização na utilização desses mecanismos.

Os desafios relacionados à educação estão em todas as áreas do saber. No caso do ensino jurídico, há uma crise constante das mais 
diversas ordens, o que inclui métodos de repassar o conhecimento em sala de aula, conforme Cintra, Camurça e Reis (2017).

Conforme Gomes e Tassigny (2018), ao analisar o ensino jurídico no Brasil na visão comparativa de Paulo Freire, constata-se que ainda ocorre nos moldes de "educação bancária", ou seja, os alunos são meros recipientes nos quais os professores enchem de conteúdo por meio de sua narração e/ou reprodução. Por isso, a necessidade da inclusão das novas tecnologias e principalmente das metodologias participativas, a qual será evidenciada mais adiante.

\section{AGENDA 2030 E OBJETIVOS DO ESTADO BRASILEIRO EM RELAÇÃO AO ENSINO}

Em 2015, os países que fazem parte da Organização das Nações Unidas para o Desenvolvimento (ONU) elaboraram agenda contendo objetivos de desenvolvimento (ODS) a serem alcançados até o ano de 2030, de acordo com os objetivos do milênio (ODM). Então, na denominada Agenda 2030 foram enumerados 17 objetivos para transformar nosso mundo.

O Objetivo n. ${ }^{\circ} 4$ da Agenda 2030 para o Desenvolvimento Sustentável trata sobre educação de qualidade, visando a "assegurar a educação inclusiva e equitativa e de qualidade, e promover oportunidades de aprendizagem ao longo da vida para todas e todos". Cada objetivo específico possui metas elencadas. Sobre o ODS 4 assunto do presente trabalho, deve ser destacada a meta de "até 2030, assegurar a igualdade de acesso para todos os homens e mulheres à educação técnica, profissional e superior de qualidade, a preços acessíveis, incluindo universidade”.

A Constituição Brasileira de 1988 elenca como um de seus objetivos a promoção do bem de todos e também consagra o direito à educação no art. 205 como sendo direito de todos e dever do estado e 
da família, sendo também o ensino livre à iniciativa privada, com o cumprimento de condições.

Registre-se ainda que, a Constituição, em seu art. 214, enumera objetivos no âmbito da educação, dentre os quais a erradicação do analfabetismo, a universalização do atendimento escolar, a melhoria da qualidade do ensino, a formação para o trabalho, a promoção humanística, científica e tecnológica do País e o estabelecimento de meta de aplicação de recursos públicos em educação em medida proporcional ao Produto Interno Bruto.

Para a legislação infraconstitucional, na Lei de Diretrizes e Bases consta a previsão expressa das disposições especiais, no art. 80, que estabelece que o Poder Público incentivará o desenvolvimento e a veiculação de programas de ensino à distância, em todos os níveis e modalidades de ensino e de educação continuada.

A promoção do ensino à distância é um dos mecanismos à disposição do Estado para a realização dos seus objetivos gerais nos termos da constituição. Assim, a experiência com o ensino jurídico à distância, após a pandemia, pode representar um mecanismo aliado ao EaD já praticado, promovendo a universalização do ensino superior.

\section{MÉTOdos DE ENSINO ATIVOS}

O contraste entre tradição e modernidade é tratado por Giddens (1991, p. 49), que aponta a reflexividade da vida social moderna, inclusive de maneira radical, envolvendo a natureza da própria reflexão, e isso significa que não se reconhece uma prática apenas por ser tradicional e que, mesmo através do conhecimento da razão, não existe segurança de que esse mesmo conhecimento não será revisado.

Nesse contexto da modernidade, o ensino jurídico é refletido por diversos autores. Gomes, Tassigny (2018) apontam a crise no ensino jurídico na contemporaneidade, propondo o uso do Direito 
alternativo, destacando a falta de espaço para criatividade, interpretação e transformação dentro das universidades.

Gomes, Tassigny (2018, p. 177) defendem que os cursos devem estabelecer como "diretriz primordial à promoção de sociedades pacíficas e inclusivas para o desenvolvimento social, como também acesso à justiça, com instituições eficazes, responsáveis e inclusivas”.

Rodrigues (2010) aponta como alternativa mais adequada para as necessidades do mundo contemporâneo a utilização de ensinoaprendizagem pela metodologia da resolução de problemas (EARP).

Com base na obra epistemológica de Karl Popper, Rodrigues (2010) enfatiza que devemos estudar problemas, não matérias, e que o aluno deve aprender a eliminar os erros, afastando as hipóteses que não resolvem o problema e mantendo aquelas que resolvem como soluções provisórias. A proposta pedagógica para o ensino jurídico defendida por Rodrigues (2010) é flexível e permite a substituição gradativa das metodologias tradicionais pelas metodologias ativas.

Em se tratando se métodos de ensino jurídico, Ghirardi (2009) apresenta de maneira resumida os principais métodos que estão sendo utilizados atualmente e que teriam virtudes e limitações próprias. Os métodos são Clínicas de Direito (CL), Ensino por Problema (Problem Based Learning - PBL), Role-Play (RP), Seminário como técnica de ensino (SM), Método do Caso (MC), Debate em sala de aula (DB) e Diálogo Socrático (DS).

O primeiro método seria a clínica, na qual o aluno entra em contato com clientes ou causa real. O método é importante, segundo Scabin e Fícca (2009), porque os casos da vida real não são estruturados, pois são apresentados pelos clientes através de narrativa. A vantagem do método seria a experiência com casos complexos e imprevisíveis, com a necessidade de que o aluno identifique as regras e os fatos relevantes.

Dificuldade extra se apresenta, no entanto, no cenário atual de pandemia, em razão do calendário e da logística do atendimento, sem o qual não é possível essa prática com os casos reais, sem mencionar 
outras dificuldades apontadas por Scabin e Fícca (2009), como o custo de manutenção, a necessidade de base teórica dos alunos e a limitação aos tipos de casos, nos casos de clínicas populares.

O método do debate é descrito por Peixoto (2009) como sendo aquele no qual os alunos participam ativamente de discussões com argumentos e contra-argumentos e que, além do conteúdo, importam a atitude e as trocas de experiências sobre o tema. As vantagens do método envolvem não apenas a apreensão de conteúdo, mas o desenvolvimento da oralidade.

Uma das problemáticas em relação à educação a distância diz respeito ao ambiente do debate, pois Peixoto (2009) enfatiza a importância de ambiente adequado, recomendando que o professor não esteja em frente aos alunos e que ocorra o contato visual direto entre os debatedores. Assim, difícil seria a reprodução de um debate em aulas remotas.

O diálogo socrático envolve, para Carvalho (2009), uma interação dialogada entre dois ou mais sujeitos, na qual se constrói coletivamente o conhecimento. O método envolve uma sequência de questões por parte do professor, a partir de diálogo com os alunos, e o diálogo segue com refutação lógica dos argumentos.

O docente instiga os alunos a apresentarem sua opinião através de questões. Carvalho (2009) expõe a preocupação de que o ambiente se torne intolerável, uma vez que para ele o método envolve forte conteúdo emocional. O diálogo socrático, nos termos propostos, é de difícil utilização na educação a distância.

Nas aulas remotas dificilmente é possível reproduzir virtualmente um diálogo coletivo com pessoas localizadas em diferentes ambientes, apesar dos avanços de algumas ferramentas que já permitem a visualização de várias pessoas ao mesmo tempo e inclusive com recurso de levantar a mão, no entanto, existe a intermediação da tela, bem como pode ser questionada a questão do vínculo entre as pessoas, que não se estabelece da mesma forma.

No método do caso, são analisadas decisões judiciais. Ramos, Schorscher (2009) enfatizam que o método permite que o estudante 
desenvolva habilidades em relação à linguagem e ao vocabulário jurídico e sobre o estudo dos argumentos utilizados. O método pode ser reproduzido em aula remota, uma vez que a discussão sobre as decisões pode ocorrer em diálogo online em tempo real.

Segundo Ferreira (2009, p.66), a aprendizagem por meio de problemas, Problem-Based Learning (PBL), pode ter definição mais ampla, inclui todos os métodos que envolvem problemas, ou mais restrita, e seria aquela na qual são analisados casos complexos, reais ou hipotéticos, que abordam elementos jurídicos e não-jurídicos e que o papel central seria do aluno facilitado pelo professor.

O método permite também a utilização em meio remoto, questionando-se apenas em relação à quantidade de alunos enquanto desvantagem também reconhecida por Ferreira (2009), pois necessita de salas pequenas.

Gabbay, Sica (2009) definem role-play como sendo o método no qual o aluno assume um papel e desenvolve dinâmicas em relação a determinado tema. A metodologia é de difícil implementação virtual, em razão da intermediação das telas dificultarem a interpretação dos papéis, porém é uma possibilidade que pode ser utilizada pelo docente, desde que devidamente planejada, com a participação dos alunos simulando papéis online.

O seminário é uma técnica de ensino participativo, segundo Machado, Barbieri (2009), na qual os alunos são o centro da atividade e recebem um tema a ser desafiado e apresentado. A metodologia é de fácil utilização na modalidade remota, no entanto, segundo os autores, para que seja bem aplicada deve envolver os demais alunos.

O ensino a distância já vinha sendo apontado como tendência antes da pandemia. Costa (2018, p.4) ressalta que "em se tratando da oferta de cursos de graduação na modalidade à distância, observa-se que o volume de oferta nesse mesmo período (2006-2016) aumentou em mais de $400 \%$, revelando uma tendência de mercado vinculada à oferta de uma nova forma de educação". 
Apesar de ser tendência, segundo Costa (2018), o ensino à distância recebe muitas críticas relacionadas à qualidade. A autora conclui pela necessidade de se refletir sobre o conservadorismo e o fechamento operacional do sistema político e educativo-jurídico relacionado ao ensino à distância, pois estaria na contramão de uma realidade.

Na mesma vertente, Moura, Tassigny, Silva (2018) tratam de método de ensino híbrido para o ensino do Direito. É proposto a utilização de ferramentas online e de metodologias ativas, dentre as quais a sala de aula invertida, como forma de engajar os estudantes e estimular o pensamento crítico, tendo o aluno como protagonista da aprendizagem e não como meramente receptor.

Até mesmo a discussão sobre o fim da sala de aula no ensino jurídico foi tratada por Ghirardi (2015), se por um lado existem ganhos em relação à democratização da educação em razão do potencial de expansão e barateamento, também existe o risco de manutenção de pensamento e engessamento de ideias.

O autor propõe a ressignificação da sala de aula a partir da inovação tecnológica e com o uso de métodos ativos. É enfatizado que aquilo que se experimenta é diferente porque se faz de maneira coletiva, dando especial ênfase à criatividade, especialmente diante da modernidade que impõe a provisoriedade do conhecimento.

A importância do coletivo e relacional não pode ser deixada de lado para Ghirardi (2015), que entende nesse sentido pela necessidade de prevalência dessa sala de aula ressignificada, até para que seja legitimada enquanto espaço de conhecimento. Conclui, o autor, que é contrário ao fim da sala de aula, defendendo, no entanto, modificações substantivas em seu funcionamento. 


\section{LEVANTAMENTO SOBRE O USO DAS AULAS REMOTAS NA OPINIÃO DOS ESTUDANTES}

A presente pesquisa investigou a percepção dos alunos do curso de Graduação em Direito das Instituições de Ensino Superior de Fortaleza acerca do uso das novas tecnologias no período de isolamento social, tendo sido permitida a utilização das aulas remotas, por meio da aplicação de um questionário de opinião com participantes não identificados, com 14 perguntas objetivas e subjetivas.

O grupo de estudantes pesquisados foi formado por alunos do curso de graduação em Direito de diversos semestres, entre faculdades, centros universitários e universidades, públicas e privadas. O número total de alunos pesquisados foi de 194, assim distribuídos: $88,1 \%$ estudam em instituições privadas e 11,9\% em instituição pública.

Passando à análise das respostas obtidas na presente pesquisa, tem-se que no gráfico 1, quanto à avaliação geral sobre as aulas remotas, os alunos demonstraram-se bem divididos quanto ao grau de satisfação, a acessibilidade da ferramenta e a interação com o professor:

Gráfico 1 - Avaliação geral sobre as aulas remotas.

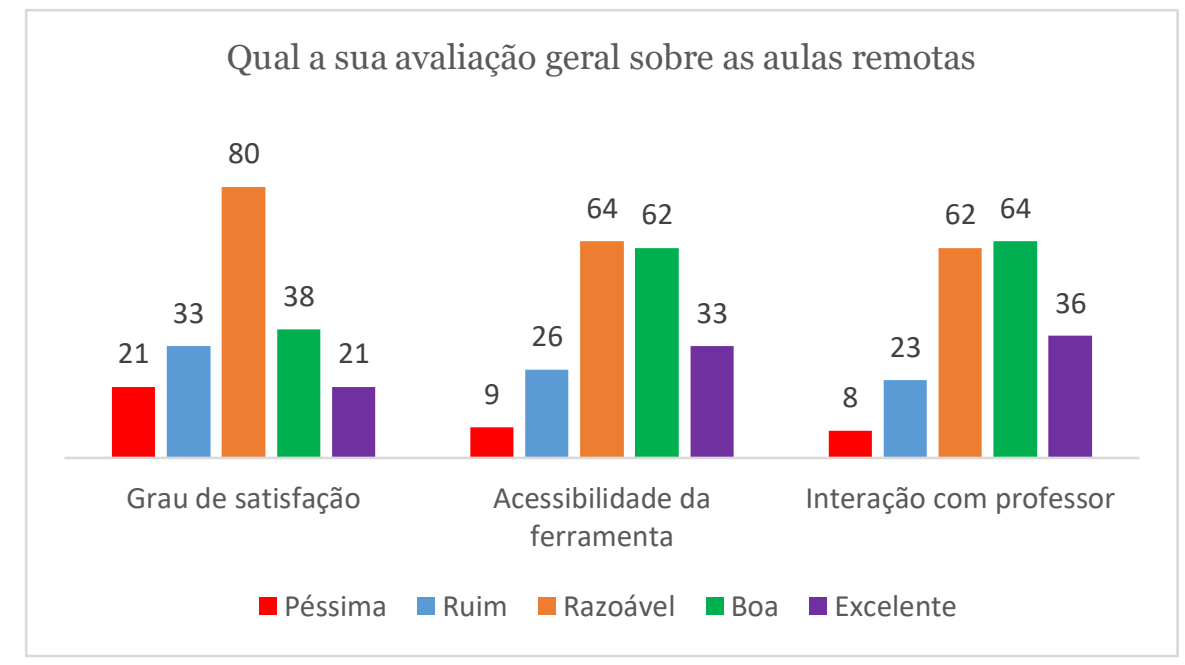

Fonte: gráfico elaborado pelas autoras. 
O gráfico 1 apresenta a opinião dos alunos em relação ao grau de satisfação, especificando-se três itens: grau de satisfação, acessibilidade da ferramenta e interação com professor. No grau de satisfação, somando-se as avaliações excelente, boa e razoável, obtevese um percentual de $72 \%$.

A acessibilidade também foi aprovada pela maioria, pois 81,95\% avalia a acessibilidade como razoável, boa ou excelente.

Em relação a interação com o professor, somadas as colunas razoável, boa e excelente, o resultado é 83,93\%, ou seja, uma ainda mais positiva avaliação nesse aspecto.

Com isso, podemos analisar que as aulas remotas neste período foram avaliadas aprovadas e consideradas satisfatórias pelos alunos consultados.

Gráfico 2 - Avaliação geral sobre as aulas remotas.

Preferência de modelo de ensino

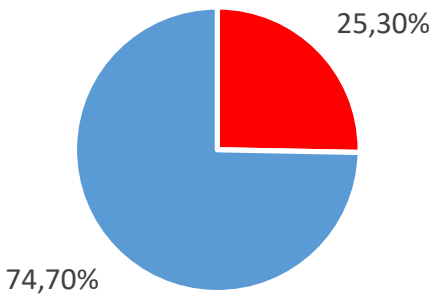

- Modelo novo de disciplina

- Retorno ao sistema anterior (disciplinas presenciais)

Fonte: gráfico elaborado pelas autoras.

No tocante às perspectivas para o futuro, de natureza opinativa, mais de 74,7\% dos alunos entrevistados entendem que, com o controle da pandemia da COVID-19 e encerrado o isolamento social, é preferível o retorno das aulas em sistema presencial.

Já na pergunta subsequente, conforme gráfico 3 cuja natureza assemelha-se à anterior por também possuir caráter factual, os alunos afirmaram, em sua grande maioria (mais de cinquenta por cento), que preferem o curso normal presencial. 
Aulas Remotas E Ensino A Distância No Período Pós-Pandemia: Um Olhar Sobre...

Gráfico 3 - Novo sistema para disciplinas.

Em caso de sistema novo, como seria a disciplina?

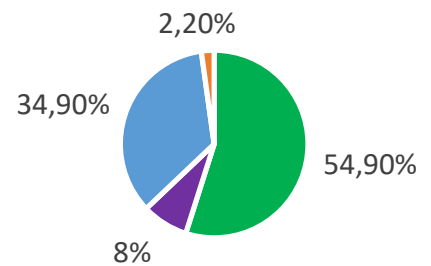

- Majoritariamente presencial

- Majoritariamente remota em tempo real

- Metade presencial e metade remoto em tempo real

- Outros

Fonte: gráfico elaborado pelas autoras.

Dessa forma, apenas $8 \%$ dos estudantes questionados responderam que utilizariam majoritariamente um sistema com aulas remotas em tempo real. As respostas analisadas verificam uma resistência dos alunos à inclusão de um novo método de ensinoaprendizagem.

Foi indagado sobre o fato de terem cursado alguma disciplina na modalidade $\mathrm{EaD}$, e as respostas foram bem divididas entre sim e não, de acordo com o gráfico 4 abaixo:

Gráfico 4 - Disciplinas EaD.

Você já fez ou faz alguma disciplina na modalidade EAD no curso de direito

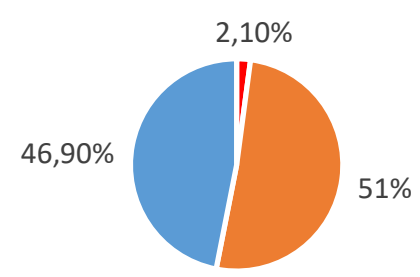

- Sim em instituição de ensino superior " sim em instituição de ensino superior pública particular

- não

Fonte: gráfico elaborado pelas autoras 
Extrai-se do levantamento realizado na pesquisa dos três últimos gráficos apresentados uma resistência didática dos alunos quanto ao mecanismo utilizado (aulas remotas) em decorrência do isolamento social, isso porque apesar de $51 \%$ já terem realizado aulas Ead, há uma preferência com percentual ainda maior, 74,7\% que opina para o retorno de aulas totalmente presenciais após a pandemia.

Outro dado analisado foi a faixa etária. Segundo Brauer (2008), aquele indivíduo que não domina as tecnologias da informação tem maiores dificuldades e resistências em relação aos cursos a distância. Nesse sentido, em relação à faixa etária dos respondentes, 66,5\% possui idade entre 20 a 30 anos, podendo-se afirmar que esses alunos já estão inseridos em ambientes virtuais. Apenas 11,9\% possuía idade superior a 60 anos.

Lapointe, Rivard (2005) sugerem que a resistência à TI pode crescer gradualmente nos graduados de acordo com a frequência que eles expressarem isso uns aos outros. Inferimos que a maioria dos entrevistados fez o curso por conta da situação que o município se encontra e não por escolha própria. Assim, existiu uma obrigatoriedade e não um interesse explícito em fazer as disciplinas nessa modalidade de aulas remotas em tempo real, também denominadas como síncronas.

Pelo exposto, concluímos que o principal motivo dos respondentes em realizar esse curso no sistema remoto deveu-se à obrigatoriedade, ou seja, não existiu espaço para aceitação ou rejeição, e sim para o cumprimento de uma determinação imposta para não serem prejudicados com o semestre letivo.

É importante ressaltar que nos Cursos de Direito, como já aludido, a resistência sempre será maior, haja vista os resultados constatados na presente pesquisa desenvolvida. Assim, vencer o tradicionalismo e o conservadorismo que assombram a "crise do ensino jurídico" enfrentada pelos Cursos de Direito continuará a ser o desafio do século XXI, seja na utilização de meios digitais ou por métodos participativos. 
Para Rojo, Sanches (2017, p. 7), o produto dessa crise é o descompasso entre o conteúdo jurídico que se opera (e o modo dessa operacionalização) e a vida além norma. Os autores Rojo, Sanches (2017, p. 8) confirmam que muito da crise do ensino do Direito nasceu por sua base essencialmente formalista, caracterizada pela reprodução da letra fria da lei; pela promoção do saber excessivamente tecnicista; e outros. Cabendo, assim, às instituições de ensino superior a possibilidade de arriscar mudar essa realidade com a inclusão das tecnologias da informação e comunicação no âmbito do ensino jurídico.

\section{CONSIDERAÇÕES FINAIS}

As mudanças no ensino jurídico já vinham sendo debatidas antes da pandemia, sendo interessante elucidar que já existia inclusive o debate sobre o fim da sala de aula. A leitura de textos com essa ênfase passa a ter mais sentido no momento da pandemia da COVID-19, no qual se verifica na prática a total impossibilidade fática da aula presencial.

Do ponto de vista dos alunos, salta aos olhos que 74,7\% defendem a manutenção do ensino presencial, apesar de terem avaliado positivamente o uso do ensino remoto enquanto ferramenta no momento de impossibilidade de aula tradicional.

A pesquisa encontrou limite em razão de não ter sido especialmente indagado o porquê da preferência pelo presencial, mesmo diante da avaliação positiva das aulas remotas. $\mathrm{O}$ resultado demonstra que é atribuída, pelos estudantes, grande importância à aula presencial, restando para nova pesquisa avaliar as razões pelas quais se atribui essa importância. 
A enquete e a discussão doutrinária demonstram que, mais importante do que substituir as aulas presenciais, deve-se repensar as metodologias aplicáveis para que envolvam maior participação dos estudantes, possibilitando desenvolver as habilidades necessárias e também promover criatividade, e, a partir da vivência coletiva, desenvolver pensamento crítico e não assimilatório de códigos e leis.

Para o futuro, a vivência do período da pandemia trouxe a familiarização com a tecnologia na área do ensino, ainda que para algumas instituições tenha demandado um esforço maior, a maioria foi capaz de providenciar o ensino remoto em até 2 semanas (93,8\%).

O fato de um número elevado, 92,78\%, de alunos terem também vivenciado atividades online extraclasse como webinars e lives demonstra que as tecnologias da informação e da comunicação (TICs) estavam subutilizadas pela academia, podendo ser utilizadas pelos docentes e possibilitando enriquecedoras experiências sem a necessidade da presença física desses profissionais.

Finalmente, uma vez que foi pesquisado em relação aos alunos, os quais opinaram em defesa do modelo presencial com percentual menor de aulas remotas, defende-se que novas pesquisas são interessantes para que se avalie também os demais envolvidos, especialmente os professores, para que, a depender da avaliação, sejam aliadas às práticas pedagógicas os momentos virtuais.

Data de Submissão: 03/07/2020

Data de Aprovação: 22/07/2020

Processo de Avaliação: double blind peer review

Editor Geral: Jailton Macena de Araújo

Editor de Área: Fernando Joaquim Ferreira Maia

Assistente Editorial: Andréa Neiva Coelho 


\section{REFERÊNCIAS}

BRASIL. Constituição (1988). Constituição da República

Federativa do Brasil: texto constitucional promulgado em 5 de outubro de 1988, com as alterações determinadas pelas Emendas Constitucionais de Revisão n. 1 a 6/94, pelas Emendas Constitucionais n. 1/92 a 91/2016 e pelo Decreto Legislativo n. 186/2008. Brasília: Senado Federal, 2016. Disponível em: https://www2.senado.leg.br/bdsf/bitstream/handle/id/518231/CF8 8_Livro_EC91_2016.pdf. Acesso em: 20 maio 2020.

BRASIL. Decreto 9.057, de 25 de maio de 2017. Regulamenta o art. 80 da Lei ${ }^{\circ}$ 9394, de 20 de novembro de 1996, que estabelece as diretrizes e bases da educação nacional, Brasília, DF, maio 2017.

BRASIL. Ministério da Educação. Parecer Conselho Pleno do Conselho Nacional de Educação no 5/2020. Disponível em: http://portal.mec.gov.br/index.php?option=com_docman\&view=do wnload\&alias=145011-pcpo05-20\&category_slug=marco-2020pdf\&Itemid=30192. Acesso em: 11 junho 2020 .

BRASIL. Ministério da Educação. Portaria 343 de 17 de março de 2020. Diário Oficial da União: edição 53, seção 1, página 39. Brasília, DF, 18 de março 2020.

BRASIL. Senado Federal. LDB: lei de diretrizes e bases da educação nacional. Brasília: Senado Federal Coordenação de Edições Técnicas, 2017. Disponível em:

http://www2.senado.leg.br/bdsf/bitstream/handle/id/529732/lei_d e_diretrizes_e_bases_1ed.pdf. Acesso em: 20 maio 2020.

\section{BRAUER, M. Resistência à Educação a Distância na}

Educação Corporativa. 188f. Tese (Doutorado em Administração de Empresas) - Programa de Mestrado Acadêmico e Doutorado em Administração de Empresas da Fundação Getúlio Vargas, São Paulo, 2008.

CARVALHO, Leonardo Arquimio de. Diálogo Socrático. In: GHIRARDI, José Garcez (org.). Métodos de Ensino em Direito: Conceitos para um Debate. São Paulo: Saraiva, 2009. p. 31-48.

CEARÁ, Decreto 33.510, de 16 de março de 2020. Diário Oficial do Estado: série 3, ano XII, no. 53. Caderno1/4. Fortaleza, CE, 16 de março 2020.

CEARÁ, Decreto 33.536, de 5 de abril de 2020. Diário Oficial do Estado: série 3, ano XII, no. 69. Caderno único. Fortaleza, CE, 5 de abril 2020. 
CEARÁ, Decreto 33.544, de 19 de abril de 2020. Diário Oficial do Estado: série 3, ano XII, no. 79. Caderno único. Fortaleza, CE, 19 de abril 2020.

CEARÁ, Decreto 33.574, de 5 de maio de 2020. Diário Oficial do Estado: série 3, ano XII, no. 91. Fortaleza, CE, 5 de maio 2020.

CEARÁ, Decreto 33.594, de 20 de maio de 2020. Diário Oficial do Estado: série 3, ano XII, no. 102. Fortaleza, CE, 20 de maio 2020.

CEARÁ, Decreto 33.608, de 30 de maio de 2020. Diário Oficial do Estado: série 3, ano XII, no. 110. Caderno Único. Fortaleza, CE, 30 de maio 2020.

CINTRA, Carlos César Sousa; CAMURÇA, Eulália Emília Pinho. REIS, Ulisses Levy Silvério dos. O uso de novas tecnologias de informação e comunicação nas salas de aula da Faculdade de Direito da Universidade Federal do Ceará: ferramentas agregadoras ou disruptivas do processo de ensino-aprendizagem? Revista Nomos, Fortaleza, v. 37, n. 2, 2017.

COSTA, Bárbara Silva. EDUCAÇÃO A DISTÂNCIA E ENSINO JURÍDICO NO BRASIL: UM DEBATE NECESSÁRIO. Revista de Pesquisa e Educação Jurídica | e-ISSN: 2525-9636 | Salvador | v. $4 \mid$ n. $1 \mid$ p. 1- 17 | Jan/Jun. 2018. Disponível em https://www.indexlaw.org/index.php/rpej/article/view/4063/pdf. Acesso em: 11 junho 2020.

GABBAY, Daniela Monteiro e SICA, Lígia Paula Pires. Role-Play. In: GHIRARDI, José Garcez. (Org). Métodos do Ensino em Direito: Conceitos para um debate. São Paulo: Saraiva, 2009. p. 73-87.

GHIRARDI, José Garcez (org) et all. Métodos de Ensino em Direito: Conceitos para um Debate. São Paulo: Saraiva, 2009.

GHIRARDI, José Garcez. Ainda Precisamos da Sala de Aula? Inovação tecnológica, metodologias de ensino e desenho institucional nas faculdades de Direito. São Paulo: FGV Direito SP, 2015.

GHIRARDI, José Garcez. O instante do encontro: questões fundamentais para o ensino jurídico. São Paulo: Fundação Getúlio Vargas, 2012.

GIDDENS, Anthony. As consequências da modernidade. São Paulo: Editora Unesp, 1991. Tradução Raul Fiker.

GOMES, C. T. M.; TASSIGNY, M. M. A crise do ensino jurídico no brasil sob a perspectiva do uso do direito alternativo. Prisma Jurídico, v. 17, p. 159-179, 2018.

GOMES, Luiz Fernando. EAD no Brasil: perspectivas e desafios. Avaliação (Campinas), Sorocaba, v. 18, n. 1, p. 13-22, mar. 2013. 
Disponível em

http://www.scielo.br/scielo.php?script=sci_arttext\&pid=S141440772013000100002\&lng =pt\&nrm=iso. acessos em 10 maio 2020. http://dx.doi.org/10.1590/S1414-40772013000100002.

LAPOINTE, L.; RIVARD, S. A multilevel model of resistance to information technology implementation. MIS Quarterly, v. 29, n. 3, p. 461-469, 2005.

MACHADO, Ana Mara Franca; BARBIERI, Catarina Helena Cortada. Seminários. In: GHIRARDI, José Garcez (org.). Métodos de Ensino em Direito: Conceitos para um Debate. São Paulo: Saraiva, 2009. p. 89-100.

MOORE, Michael G. Educação a distância: uma visão integrada / Michael G. Moore, Greg Kearsley. Tradução Roberto Galman. São Paulo : Cengage Learning, 2007.

MOURA, Taísa Ilana Maia de; TASSIGNY, Mônica Mota; SILVA, Thomaz Edson Veloso. O USO DA TECNOLOGIA NO ENSINO JURÍDICO: o método do ensino híbrido no curso de direito. Revista Univap, [s.l.], v. 24, n. 45, p. 70, 31 out. 2018. UNIVAP Universidade de Vale do Paraiba.

http://dx.doi.org/10.18066/revistaunivap.v24i45.2018.

OLIVEIRA, Claúdio de; MOURA, Samuel Pedrosa; SOUSA, Edinaldo Ribeiro de. TIC'S NA EDUCAÇÃO:: a utilização das tecnologias da informação e comunicação na aprendizagem do aluno. Pedagogia em Ação, Minas Gerais, v. 1, n. 7, p. 75-95, 30 abr. 2020. Semestral. Disponível em:

http://periodicos.pucminas.br/index.php/pedagogiacao/. Acesso em: 30 abr. 2020.

ORGANIZAÇÃO DAS NAÇÕES UNIDAS. A Agenda 2030.

Disponível em: https://nacoesunidas.org/pos2015/agenda2030/. Acesso em: 10 jun 2020.

PEIXOTO, Daniel. Debate. In: GHIRARDI, José Garcez (org.).

Métodos de Ensino em Direito: Conceitos para um Debate. São

Paulo: Saraiva, 2009. p. 23-30.

PEREIRA, Thomas Henrique Junqueira de Andrade. Problem-Based Learning (PBL). In: GHIRARDI, José Garcez (org.). Métodos de Ensino em Direito: Conceitos para um Debate. São Paulo: Saraiva, 2009. p. 61-72.

RAMOS, Luciana; SCHORSCHER, Vivian. Método do Caso. In: GHIRARDI, José Garcez (org.). Métodos de Ensino em Direito: Conceitos para um Debate. São Paulo: Saraiva, 2009. p. 49-6o. 
REIS, Júnias Belmont Alves dos. O conceito de Tecnologia e Tecnologia Educacional para alunos do ensino médio e superior. UCDB. 2010. Disponível em: http://alb.com.br/arquivomorto/edicoes_anteriores/anais17/txtcompletos/sem16/COLE_932. pdf. Acessado em: 07 de Outubro, 2019.

RODRIGUES, Horácio Wanderlei. Popper e o processo de ensinoaprendizagem pela resolução de problemas. Revista Direito Gv, [s.l.], v. 6, n. 1, p. 39-57, jun. 2010. Fap UNIFESP (SciELO). http://dx.doi.org/10.1590/s1808-24322010000100003.

ROJO, A.; SANCHES, R. C. F. Metodologia Ativa: Possível Instrumento para um Ensino Jurídico voltado à Inclusão Social. Prim@Facie, v. 16, n. 33, p. 01-21, 27 nov. 2017.

SCABIN, Flávia; FÍCCA, Thiago. Clínica de Direito. In: GHIRARDI, José Garcez (org.). Métodos de Ensino em Direito: Conceitos para um Debate. São Paulo: Saraiva, 2009. p. 1-22.

SILVA, Celimar Barreto Oliveira. Instrução programada: tecnologia educacional aplicada ao ead. Revista de Tecnologia Aplicada (Rta), Campo Limpo Paulista, v. 3, n. 4, p. 32-52, dez. 2015. Quadrimestral. Disponível em: http://www.cc.faccamp.br/ojs-2.4.82/index.php/RTA/index. Acesso em: 30 abr. 2020.

SILVA, Marco (2001). Sala de aula interativa: a educação presencial e a distância em sintonia com a era digital e com a cidadania. In: CONGRESSO BRASILEIRO DA COMUNICAÇÃO, 24., 2001, Campo Grande. Anais do XXIV Congresso Brasileiro da Comunicação, Campo Grande: CBC, set. 2001. 


\title{
Remote Classes And Distance Education In The After- Pandemic Period: A View About The Legal Education Through The Perspective Of The University Students In Fortaleza
}

\author{
Daiane Queiroz
}

\author{
Ana Carolina Neiva Gondim Ferreira Gomes
}

Mônica Mota Tassigny

\begin{abstract}
Due to the social distance caused by COVID-19 pandemic, remote education is now allowed by Resolution No. 342 of March 17, 2020. Exceptionally, the replacement of classroom courses in progress by classes using means and information and communication technologies (ICTs) was authorized. Based on this practice, seeks to analyze the opinion of undergraduate law students in Fortaleza about remote classes, subjects in distance education (EAD) and perspectives for the future of legal education. This study is based on bibliographic, documents and field research, with a sample of 194 students from higher education in the city of Fortaleza. Qualitative and quantitative approaches were used. It turns out that there is a majority preference, $74.7 \%$, for the return of traditional presential classes mainly, with smaller percentage of remote classes, but lower than $30 \%$. As a result, it is expected to contribute to the improvement of legal education in Brazil based on the analysis of this new remote classroom teaching mechanism.
\end{abstract}

Keywords: Pandemic. Covid-19. Law education. Remote Classes. Law Courses. 